\title{
RESTORATION OF ANGIOGENESIS BY ENALAPRIL IN DIABETIC HINDLIMB ISCHEMC RATS
}

\author{
Ali Reza Fallahzadeh, Majid Khazaei*, Mohammad Reza Sharifi
}

\author{
Department of Physiology, Isfahan University of Medical Sciences, Isfahan, Iran \\ E-mail:majkhazaei@yahoo.com
}

Received: October 27, 2010; Accepted with revision: March 29, 2011

Key words: Diabetes/Hind limb ischemia/Capillary density/Enalapril/Rat

Background. Angiotensin-converting enzyme inhibitors have different effects on the cardiovascular system. The aim of this study was to investigate the effect of enalapril on skeletal muscle angiogenesis in diabetic and diabetic hind limb ischemic rats.

Methods. We studied 24 male diabetic rats (induced by streptozotocin, $55 \mathrm{mgkg}$, ip) divided into four groups. Groups 1 and 2 were diabetic sham (surgical procedure without femoral artery ligation). Groups 3 and 4 were diabetic animals subjected to induced hind limb ischemia. Groups 2 and 4 received enalapril ( $15 \mathrm{mg} / \mathrm{kg} /$ day, i.p) and groups 1 and 3 received an equal volume of saline. After 21 days, capillary density, capillary to fiber (capfib) ratio and serum concentrations of nitric oxide (NO), Vascular Endothelial Growth Factor (VEGF) and soluble VEGF Receptor-1 (sVEGF-R1) were evaluated.

Results. Enalapril significantly increased serum NO and VEGF concentrations and reduced serum sVEGF-R1 concentrations in diabetic sham and hind limb ischemic rats $(p<0.05)$. Administration of enalapril significantly increased capillary density and cap/fib ratio in diabetic sham and hind limb ischemic animals compared with nontreated groups $(\mathrm{p}<0.05)$.

Conclusions. Enalapril restores skeletal muscle angiogenesis in diabetic hind limb ischemia and can be considered for the prevention and treatment of peripheral artery disease in diabetic subjects.

\section{INTRODUCTION}

Peripheral artery disease is a major cause of morbidity and mortality in developed countries ${ }^{1}$. Diabetes is one of the most important risk factors for the development of peripheral vascular disease ${ }^{2}$. For this reason, therapeutic angiogenesis is one approach to improving tissue perfusion and clinical outcome in diabetic subjects.

Angiogenesis is the proliferation of new blood vessels from preexisting vascular structures and it plays an important role in physiological and pathological conditions $^{3}$. Altered angiogenesis in diabetic states have been demonstrated in experimental and clinical studies. Peripheral artery disease and alteration in skeletal muscle microvasculature in the course of diabetes leads to tissue ischemia which may result in ulceration and amputation of the lower extremities ${ }^{4,5}$.

The renin-angiotensin-aldosterone system plays a key role in the regulation of blood pressure and vascular response to injury ${ }^{6,7}$. Recent studies suggested that angiogensin II and Angiotensin-Converting Enzyme (ACE) inhibitors are involved in angiogenesis ${ }^{8}$. In this study, we used the hind limb ischemia model which is well established for studying skeletal muscle angiogenesis ${ }^{9}$. The aim was to evaluate the effect of enalapril, an ACE inhibitor, on angiogenesis and serum nitric oxide (NO), Vascular Endothelial Growth Factor (VEGF), and soluble VEGF Receptor-1 (sVEGF-R1) in diabetic and diabetic hind limb ischemic rats.

\section{MATERIALS AND METHODS}

\section{Animals}

Male wistar rats $(n=24)$ weighing between $230 \pm 30 \mathrm{~g}$ (10-12 weeks old) were obtained from the Pasteur Institute of Iran. The animals were housed three per cage in an airconditioned animal room with $12 \mathrm{~h}$ light/dark cycle and humidity around $60-70 \%$ at a room temperature between 20-25 ${ }^{\circ} \mathrm{C}$. The animals were fed with a standard pellet diet with free access to usual drinking water during the study. All procedures and protocols used were approved by the ethics committee of Isfahan University of Medical Sciences and were in accordance with the guiding principles for the care and use of laboratory animals.

\section{Induction of diabetes}

Diabetes was induced by single intraperitoneal injection of streptozotocin $(55 \mathrm{mg} / \mathrm{kg}$ ) dissolved in $0.9 \%$ saline. After $48 \mathrm{~h}$, diabetes was verified by blood glucose concentration higher than $16.7 \mathrm{mmol} / 1$ ( ref. $\left.^{10}\right)$. The control group received $\mathrm{N} / \mathrm{S}$ injection with the same volume.

\section{Rat ischemic hind limb model}

The rats were anesthetized with $75 \mathrm{mg} / \mathrm{kg}$ ketamine and $7.5 \mathrm{mg} / \mathrm{kg}$ xylazine for unilateral femoral artery ligation. First, the surgical site was shaved. Through a small incision on the medial side of the left thigh, the left femoral artery was isolated. The femoral artery and 
Table 1. Body weight and blood glucose concentration in all experimental groups.

\begin{tabular}{|c|c|c|c|c|c|}
\hline \multirow{2}{*}{ Groups } & $\mathrm{n}$ & \multicolumn{2}{|c|}{ Body weight (g) } & \multicolumn{2}{c|}{ Blood glucose concentration (mmol/1) } \\
\hline & & day 0 & day 21 & day 0 & day 21 \\
\hline Diabetic sham & 6 & $232 \pm 9.82$ & $169 \pm 10.77^{*}$ & $30.64 \pm 1.13$ & $29.66 \pm 2.78$ \\
\hline $\begin{array}{c}\text { Diabetic sham }+ \\
\text { Enalapril }\end{array}$ & 6 & $240 \pm 8.27$ & $178.3 \pm 7.60^{*}$ & $26.77 \pm 1.56$ & $27.57 \pm 2.09$ \\
\hline $\begin{array}{c}\text { Diabetic hind limb } \\
\text { ischemia }\end{array}$ & 6 & $245 \pm 7.19$ & $198.67 \pm 9.53^{*}$ & $30.39 \pm 1.20$ & $31.16 \pm 1.18$ \\
\hline $\begin{array}{c}\text { Diabetic hind limb } \\
\text { ischemia + Enalapril }\end{array}$ & 6 & $242.5 \pm 6.68$ & $190 \pm 4.28^{*}$ & $31.74 \pm 1.08$ & $32.01 \pm 0.99$ \\
\hline
\end{tabular}

Values are presented as mean $\pm S E .{ }^{*} p<0.05$ vs. day 0 .

all its major branches were completely ligated with 3-0 surgical silk ${ }^{9,11}$. Then, the wounds were sutured and the animals were allowed to recover in their cages. The animals appeared recovered within $48 \mathrm{~h}$ with no signs of tissue necrosis.

\section{Experimental design}

The animals were randomly divided into four groups ( $\mathrm{n}=6$ each). Groups 1 and 2 were diabetic sham (DS) (surgical procedure without femoral artery ligation). Groups 3 and 4 were diabetic animals subjected to induced hind limb ischemia (DH). The animals in groups 2 and 4 received ACE inhibitor, enalapril ( $15 \mathrm{mg} / \mathrm{kg}$, i.p) and groups 1 and 3 received an equal volume of saline. Enalapril was dissolved in saline and administered daily for a period of 3 weeks ${ }^{9,12}$.

Blood samples were taken from all animals before and at the end of the experiment and centrifuged in $3000 \mathrm{c} / \mathrm{s}$ for $20 \mathrm{~min}$. The sera were poured into Eppendorff tubes and stored at $-70{ }^{\circ} \mathrm{C}$ for serum NO, VEGF and soluble VEGF Receptor-1 (sVEGF- R1) measurements. At the end of the experiment, the animals were sacrified. Gastrocnemius muscles from the left limb of the animals were removed and fixed in formalin solution immediately for immunohistochemical evaluation.

\section{Serum NO measurement}

Serum NO concentrations were determined by evaluation of its metabolite (nitrite) using Griess reagent method (Promega Corp, Madison, USA) as described previously ${ }^{9,13}$.

\section{Serum VEGF and sVEGF-RI measurements}

Serum VEGF and sVEGFR1 concentrations were measured by Enzyme-linked Immunosorbent assay using available reagents and recombinant standards (R8D systems, Minneapolis, USA).

\section{Capillary density analysis}

For analysis of capillary density, histological sections $(5 \mu \mathrm{m})$ were prepared from each muscle sample. Capillary endothelial cells were identified by immunohistochemical staining with rat monoclonal antibody directed against mouse CD31 (Abcam, Cambridge UK) ${ }^{8,14}$.

Capillary endothelial cells were counted by a light microscope. Fifteen microscopic fields $(\times 400)$ from three different sections in each tissue block were randomly selected and number of capillaries was determined by two blinded observers. To ensure that capillary density was not overestimated or underestimated because of muscle atrophy or interstitial edema, respectively, capillary/muscle fiber ratio was also expressed. Capillary and fiber density were determined as the number of capillaries or fibers per $\mathrm{mm}^{2}$.

\section{Statistical analysis}

Values are expressed as mean \pm SE. The student's paired $t$ test was used to analyse data. One-way ANOVA using tukey's post hoc test was used to compare data between groups. A $p$ value equal to or less than 0.05 was considered statistically significant.

\section{RESULTS}

\section{Body weight and blood glucose}

Body weight and blood glucose concentration are shown in (Table 1). After 21 days, the body weight of animals in all groups significantly decreased compared to day $0(p<0.05)$. Blood glucose concentrations were maintained higher than $16.7 \mathrm{mmol} / 1$ in all groups throughout the study. The treatment of diabetic rats with enalapril did not cause any significant changes in body weight or blood glucose concentrations compared to controls ( $p>0.05$ ). 


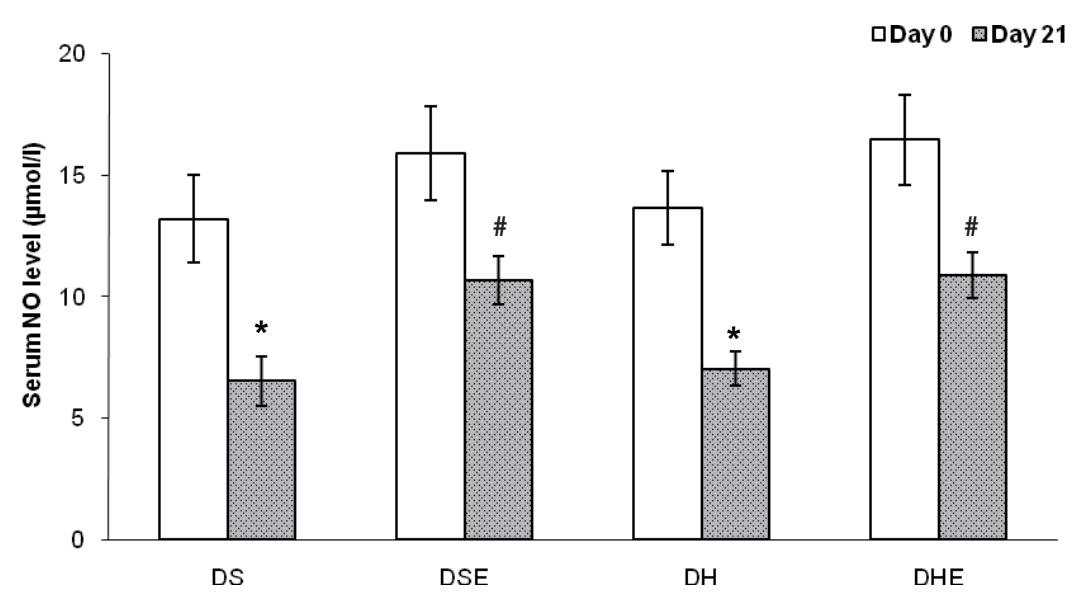

Fig. 1. Serum NO concentrations in experimental groups before (day 0 ) and after experiment (day 21). Values are expressed as mean $\pm \mathrm{SE}, \mathrm{n}=6$ per group. ${ }^{*} \mathrm{p}<0.05$ vs. day 0 , ${ }_{\mathrm{p}}<0.05$ vs. non-treated groups. DS: diabetic sham. DSE: diabetic sham rats treated with enalapril. DH: diabetic hind limb ischemia. DHE: diabetic hind limb ischemic rats treated with enalapril.

A

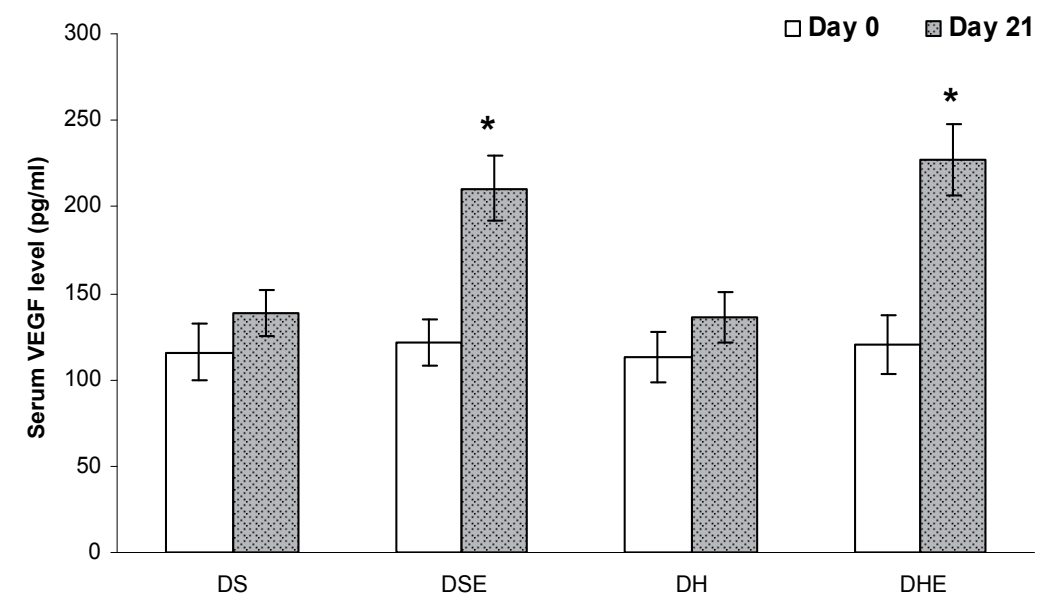

B

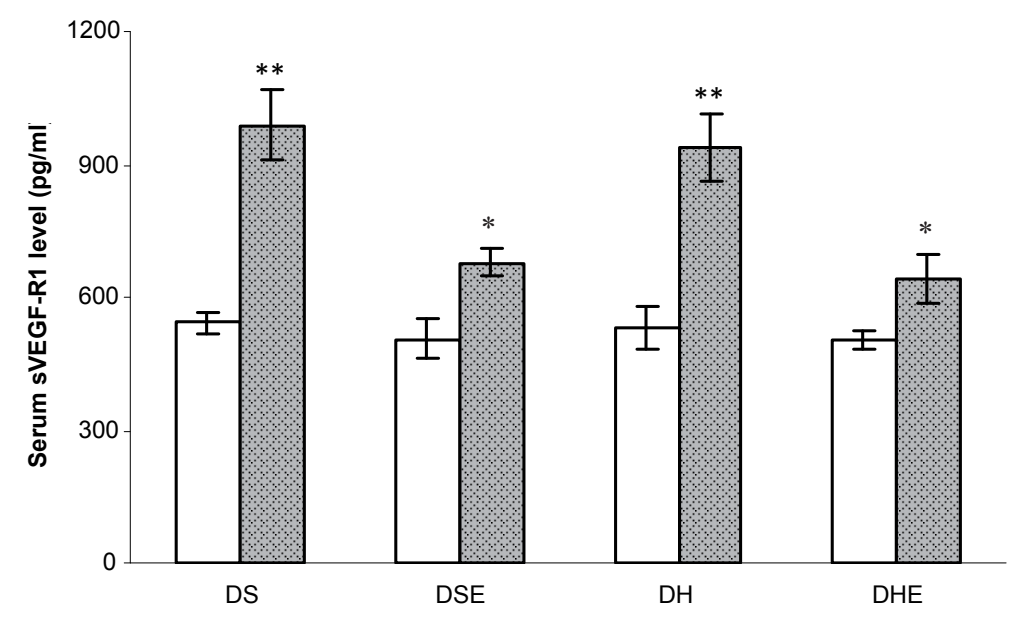

Fig. 2. Effects of enalapril on serum VEGF (A) and sVEGF-R1 (B) concentrations in diabetic sham and diabetic hindlimb ischemic rats. Values are expressed as mean \pm SE, $n=6$ per group. ${ }^{*} p<0.05 v$ s. diabetic non-treated group; ${ }^{* *}$ p $<0.05$ vs. day 0 . 

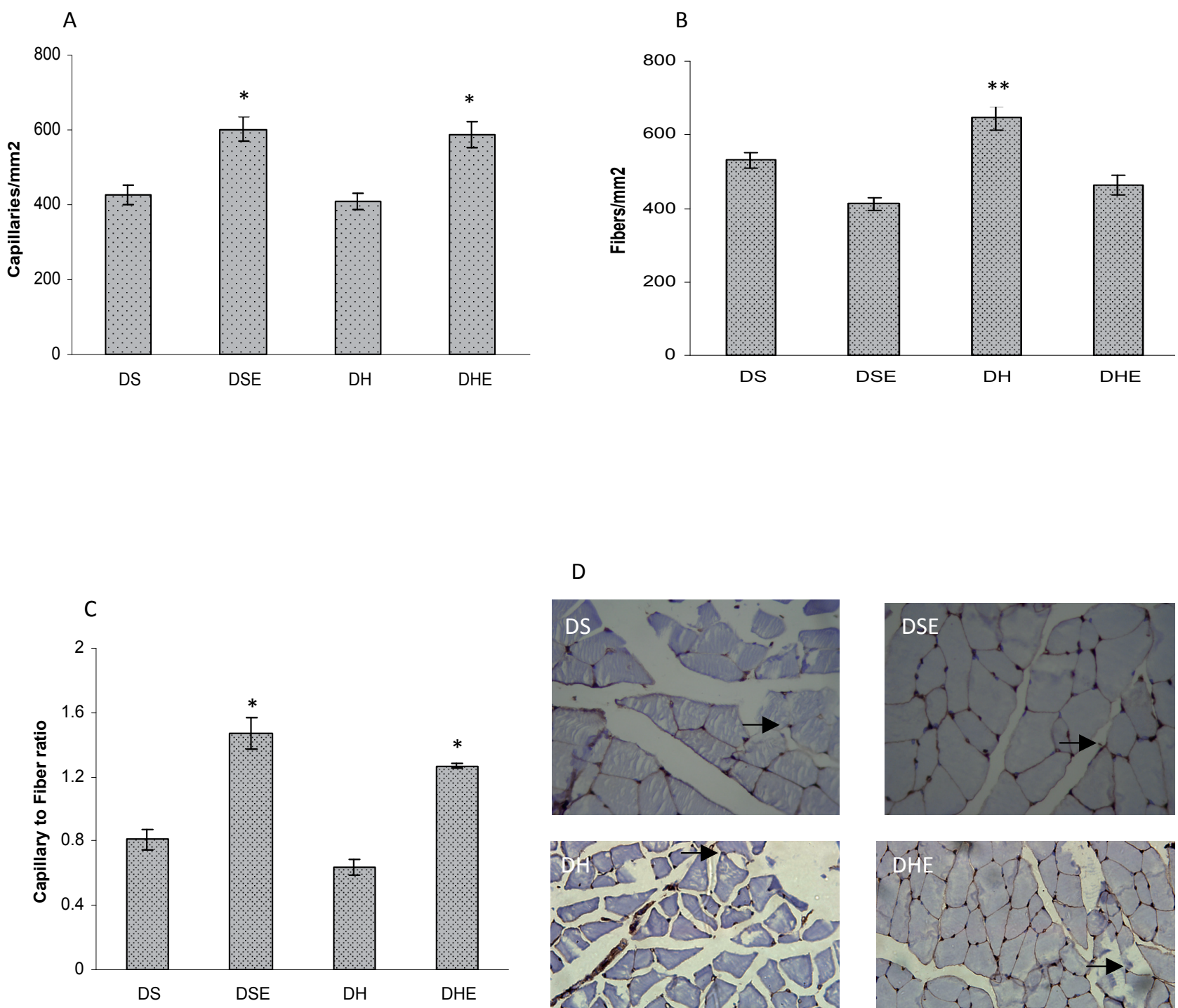

D

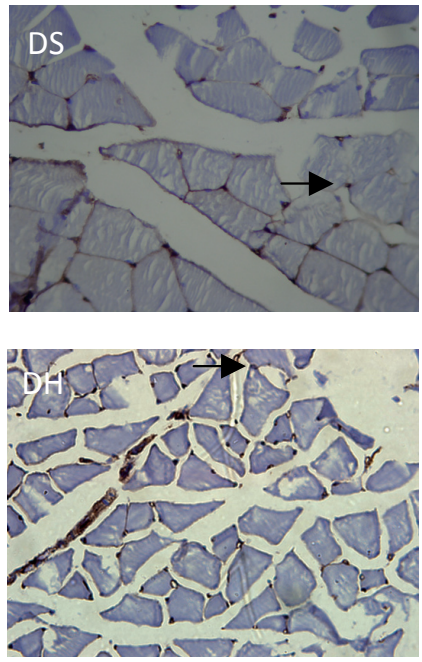

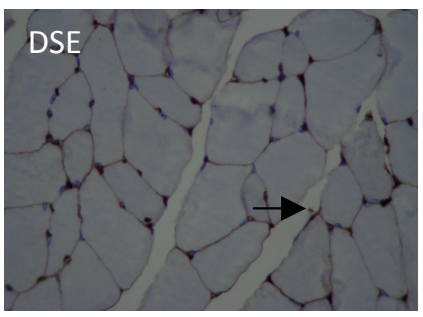

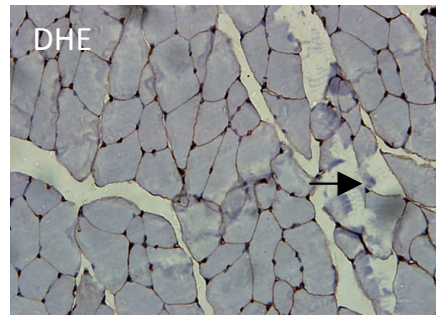

Fig. 3. Effects of enalapril on capillary density (A), fiber density (B) and Cap/Fib ratio (C) in diabetic and diabetic hind limb ischemic rats. D: Representative images of immunohistochemical staining with an anti-CD31 monoclonal antibody of skeletal muscle tissues in experimental groups at postoperative day $21(\times 400)$. Values are mean \pm SE, $n=6$ per group. ${ }^{*} \mathrm{p}<0.05$ vs. diabetic non-treated groups. ${ }^{* *} \mathrm{p}<0.05$ vs. other groups.

\section{Serum NO concentrations}

(Fig. 1) shows serum concentrations of NO before and after treatment with enalapril in DS and DH groups. On day 0 , there were no significant differences in serum NO concentrations between experimental groups. After 21 days, serum NO concentrations were decreased in DS and DH groups. Enalapril significantly increased serum NO concentrations in diabetic sham and hind limb ischemic rats $(\mathrm{p}<0.05)$.

\section{Serum VEGF and SVEGF-RI concentrations}

(Fig. 2) illustrates serum concentrations of VEGF and sVEGF-R 1 on day 0 and after 21 days treatment with enalapril. On day 0 , there were no significant differences in serum concentrations of VEGF or sVEGF-R1 between experimental groups. Enalapril significantly increased serum VEGF concentration in DS and DH groups compared with non-treated groups (Fig. 2A). In addition, treatment with enalapril decreased serum sVEGF-R1 concentrations in DS and DH groups (Fig. 2B).

\section{Effects of enalapril on capillary density, muscle fiber density and capillary to muscle fiber ratio}

We investigated capillary density (number of capillaries per $\mathrm{mm}^{2}$ ), fiber density (number of fibers per $\mathrm{mm}^{2}$ ), and capillary to muscle fiber (Cap/Fib) ratio in histological sections harvested from left gasterocnemius muscles in experimental groups. Administration of enalapril significantly increased capillary density and decreased fiber density in DS and DH groups (Fig. 3A,B). In addition, 
enalapril increased Cap/Fib ratio compared with control groups (Fig. 3C). Samples of histological section of skeletal muscles are presented in (Fig. 3D).

\section{DISCUSSION}

We investigated the effect of enalapril on angiogenesis in response to hind limb ischemia in diabetic rats. Administration of enalapril significantly increased serum concentrations of NO and VEGF, and reduced sVEGF$\mathrm{R} 1$ concentrations. In addition, enalapril significantly increased capillary density and $\mathrm{CapFib}$ ratio in diabetic and in diabetic hind limb ischemic rats.

Angiogenesis is a physiological response to ischemia and defined as sprouting of new vessels from preexisting vasculature. Several angiogenic factors are suggested to be involved in this process including NO, VEGF, and VEGF receptors. Angiogenic growth factors enhance neovascularization in patients with limb ischemia ${ }^{15}$.

Diabetes is associated with micro- and macrovascular abnormalities in some tissues leading to retinopathy, nephropathy and/or neuropathy and is a risk factor for peripheral vascular disease ${ }^{16,17}$. The present study showed reduced serum concentrations of NO and VEGF after induction of diabetes. Diabetes affects angiogenic and anti-angiogenic factors ${ }^{17}$ and is associated with abnormal angiogenesis depending on the type of tissue. Neovascularization in some tissues such as the retina and impaired collateral formation in other tissues such as cardiac tissue suggest that diabetes differentially alters angiogeneic factors ${ }^{18}$. Published studies have reported that eNOS, VEGF and bFGF mRNA decrease during diabetes $^{19-21}$. Further, VEGF ligand signaling is lower in diabetic mice compared with control mice ${ }^{22,23}$. In contrast, it is suggested that lower expression of angiogenic factors is not responsible for microangiopathy in diabetic ischemic tissue $^{24}$. This contradiction may raise from differences in species and/or in the duration of the diabetes ${ }^{17}$. VEGF has two receptors: VEGF-R1 and VEGF-R2. Soluble form of VEGF-R1 (sVEGF-R1) acts as an inhibitor of angiogenesis. It negatively modulates the angiogenic effects of VEGF-R2 and could reduce the bioavailability of $\mathrm{VEGF}^{25,26}$. In this experiment, serum sVEGF-R1 concentrations significantly increased during diabetes. Over expression of VEGF-R1 and sVEGF-R1 in diabetic animals has been reported ${ }^{22}$.

ACE inhibitors are widely used as antihypertensive drugs. Recently, studies reported the beneficial effects of ACE inhibitors on tumor growth by inhibiting neovascularization ${ }^{27,28}$ and in myocardial ischemia by improving angiogenesis ${ }^{29}$. In this study, we found that enalapril increased angiogenesis in diabetic and diabetic hind limb ischemic rats. In agreement with our results, a recent study reported that diabetes is associated with reduced neovascularization and that perindopril improved postischemic revascularization ${ }^{19}$. These authors suggested that the proangiogenic effect of ACE inhibitors was mediated at least in part by the bradykinin receptor and activation of VEGF and NO pathways ${ }^{18,19}$. In the present study, we found that enalapril increased serum NO and VEGF concentrations and reduced sVEGF-R1 concentrations in diabetic rats. Reduction in VEGF-R1 improves the ability of VEGF to bind to VEGF-R2 ${ }^{25,26}$. Thus, increase in angiogenic factors and reduction in VEGF-R1 support the role of enhanced angiogenesis in enalapril-treated diabetic animals.

Changes of capillary density in enalapril-treated groups may be related to reduction in blood pressure. In this study, we did not measure blood pressure and this is a limitations of our study. On the other hand, the effect of high/low blood pressure per se on angiogenesis process remains unclear ${ }^{18}$.

In conclusion, enalapril restores skeletal muscle angiogenesis in diabetic and diabetic hind limb ischemia in rats and can be considered for the prevention and treatment of peripheral vascular complications in diabetic subjects.

\section{ACKNOWLEDGMENT}

We thank H. Sadeghi for technical assistance. This work was supported by Isfahan University of Medical Sciences (Grant \#188103).

\section{REFERENCES}

1. Ouriel K. Peripheral arterial disease. Lancet 2001;358:1257-64.

2. Beckman JA, Creager MA, Libby P. Diabetes and atherosclerosis: epidemiology, pathophysiology, and management. JAMA 2002;287:2570-81.

3. Folkman J. Angiogenesis. Annu Rev Med 2006;57:1-18.

4. Sheetz MJ, King GL. Molecular understanding of hyperglycemia's adverse effects for diabetic complications. JAMA 2002;288:257988.

5. Silvestre JS, Levy BI. Molecular basis of angiopathy in diabetes mellitus. Circ Res 2006;98:4-6.

6. Weir MR. Effects of renin-angiotensin system inhibition on endorgan protection: can we do better? Clin Ther 2007;29:1803-24.

7. Sasaki K, Murohara T, Ikeda H, Sugaya T, Shimada T, Shintani $\mathrm{S}$, Imaizumi,T. Evidence for the importance of angiotensin II type 1 receptor in ischemia-induced angiogenesis. J Clin Invest 2002;109:603-11.

8. Li P, Kondo T, Numaguchi Y, Kobayashi K, Aoki M, Inoue N, Okumura K, Murohara T. Role of bradykinin, nitric oxide, and angiotensin II type 2 receptor in imidapril-induced angiogenesis. Hypertension 2008;51:252-58.

9. Lloyd PG, Yang HT, Terjung RL. Arteriogenesis and angiogenesis in rat ischemic hindlimb: role of nitric oxide. Am J Physiol Heart Circ Physiol 2001;281:H2528-H2538.

10. Taniyama Y, Morishita R, Hiraoka K, Aoki M, Nakagami H, Yamasaki K, Matsumoto K, Nakamura T, Kaneda Y, Ogihara T. Therapeutic angiogenesis induced by human hepatocyte growth factor gene in rat diabetic hind limb ischemia model: molecular mechanisms of delayed angiogenesis in diabetes. Circulation 2001;104:2344-50.

11. Nematollahi S, Nematbakhsh M, Haghjooyjavanmard S, Khazaei M, Salehi M. Inducible nitric oxide synthase modulates angiogenesis in ischemic hindlimb of rat. Biomed Pap Med.Fac Univ Palacky Olomouc Czech Repub 2009;153:125-29.

12. Baluchnejadmojarad T, Roghani M, Imani A. Protective effect of enalapril on vascular reactivity of the rat aorta. Vascul Pharmacol 2004;40:301-07.

13. Khazaei M, Nematbakhsh M. The effect of hypertension on serum nitric oxide and vascular endothelial growth factor concentrations. A study in DOCA-Salt hypertensive ovariectomized rats. Regul Pept 2006;135:91-94. 
14. Nematbakhsh M, Ghadesi M, Hosseinbalam M, Khazaei M, Gharagozloo M, Dashti S, Rajabi P, Rafeian S. Oestrogen promotes coronary angiogenesis even under normoxic conditions. Basic Clin Pharmacol Toxicol 2008;103:273-77.

15. Carmeliet P. Angiogenesis in health and disease. Nat Med 2003;9:653-60.

16. Simons M. Angiogenesis, arteriogenesis, and diabetes: paradigm reassessed? J Am Coll Cardiol 2005;46:835-37.

17. Kivela R, Silvennoinen M, Lehti M, Jalava S, Vihko V, Kainulainen H. Exercise-induced expression of angiogenic growth factors in skeletal muscle and in capillaries of healthy and diabetic mice. Cardiovasc Diabetol 2008;7:13.

18. Ebrahimian TG, Tamarat R, Clergue M, Duriez M, Levy BI, Silvestre JS. Dual effect of angiotensin-converting enzyme inhibition on angiogenesis in type 1 diabetic mice. Arterioscler Thromb Vasc Biol 2005;25:65-70.

19. Gao L, Yu DM. Molecular mechanism of limbs' postischemic revascularization improved by perindopril in diabetic rats. Chin Med J (Engl.) 2008;121:2129-33.

20. Chou E, Suzuma I, Way KJ, Opland D, Clermont AC, Naruse K, Suzuma K, Bowling NL, Vlahos CJ, Aiello LP, King GL. Decreased cardiac expression of vascular endothelial growth factor and its receptors in insulin-resistant and diabetic States: a possible explanation for impaired collateral formation in cardiac tissue. Circulation 2002;105:373-79.

21. Emanueli C, Graiani G, Salis MB, Gadau S, Desortes E, Madeddu P. Prophylactic gene therapy with human tissue kallikrein ameliorates limb ischemia recovery in type 1 diabetic mice. Diabetes 2004;53:1096-103.

22. Hazarika S, Dokun AO, Li Y, Popel AS, Kontos CD, Annex BH Impaired angiogenesis after hindlimb ischemia in type 2 diabe- tes mellitus: differential regulation of vascular endothelial growth factor receptor 1 and soluble vascular endothelial growth factor receptor 1. Circ Res 2007;101:948-56.

23. Li YJ, Guan H, Hazarika S, Liu CW, Annex BH. Impaired angiogenesis following hind-limb ischemia in diabetes mellitus mice. Chin Med Sci J 2007;22:232-37.

24. Waltenberger J, Lange J, Kranz A. Vascular endothelial growth factor-A-induced chemotaxis of monocytes is attenuated in patients with diabetes mellitus: A potential predictor for the individual capacity to develop collaterals. Circulation 2000;102:185-90.

25. Roberts DM, Kearney JB, Johnson JH, Rosenberg MP, Kumar R, Bautch VL. The vascular endothelial growth factor (VEGF) receptor Flt-1 (VEGFR-1) modulates Flk-1 (VEGFR-2) signaling during blood vessel formation. Am J Pathol 2004;164:1531-35.

26. Olsson AK, Dimberg A, Kreuger J, Claesson-Welsh L. VEGF receptor signalling - in control of vascular function. Nat Rev Mol Cell Biol 2006;7:359-71.

27. Zheng Z, Chen H, Ke G, Fan Y, Zou H, Sun X, Gu Q, Xu X, HO PC. Protective effect of perindopril on diabetic retinopathy is associated with decreased vascular endothelial growth factor-to-pigment epithelium-derived factor ratio: involvement of a mitochondriareactive oxygen species pathway. Diabetes 2009;58:954-64.

28. Christian JB, Lapane KL, Hume AL, Eaton CB, Weinstock MA Association of ACE inhibitors and angiotensin receptor blockers with keratinocyte cancer prevention in the randomized VATTC trial. J Natl Cancer Inst 2008;100:1223-32.

29. Donnini S, Solito R, Giachetti A, Granger HJ, Ziche M, Morbidelli L. Fibroblast growth factor-2 mediates Angiotensin-converting enzyme inhibitor-induced angiogenesis in coronary endothelium. J Pharmacol Exp Ther 2006;319:515-22. 